\title{
Endoscopic Management of Gastric Polyp with Outlet Obstruction without Polypectomy
}

\author{
Cheuk-Kay Sun Kuo-Ching Yang Chao-Sheng Liao
}

Division of Hepatology and Gastroenterology, Department of Internal Medicine, Shin Kong Wu Ho-Su Memorial Hospital, Taipei, Taiwan

\section{Key Words}

Endoscopy · Detachable snare · Gastric polyp

\begin{abstract}
Although gastric polyp is usually an incidental endoscopic finding, large-sized polyps can cause symptoms ranging from epigastralgia to bleeding from ulcerated polyps and gastric outlet obstruction. Although the gold standard of treatment is removal of the polyp either through endoscopic polypectomy or surgical excision, complications associated with these procedures cannot be ignored. The risk becomes a major concern for patients at high risk for surgery when complications arise. We describe a debilitated 74-year-old woman who presented with early satiety, intermittent postprandial nausea and vomiting for three months. Upper endoscopy revealed a $2.5 \mathrm{~cm}$ pedunculated polyp over the gastric antrum causing intermittent obstruction. Considering her high risk for polypectomy, detachable snaring was performed without polypectomy in an outpatient setting. The patient was complication-free with complete relief of obstructive symptoms one week after the procedure. Subsequent follow-ups showed satisfactory healing without signs of mucosal disruption or recurrence. The results suggest that detachable snaring without polypectomy may be a therapeutic option for high-risk patients with benign symptomatic gastric polyps.
\end{abstract}

\section{Introduction}

Gastric polyp is a common occurrence especially in the elderly population. Although it is usually an incidental finding without symptoms, associated epigastralgia, hemorrhage from polyp ulceration, and gastric outlet obstruction from antral polyp are well documented. Treatment is also indicated for larger polyp $(>1 \mathrm{~cm})$ [1] because of the increased risk of malignant transformation. The current standard therapeutic strategy is complete removal of the polyp through either endoscopic polypectomy or surgical 
excision. Although the technical advances in endoscopic procedures have replaced the traditional need for laparotomy in the management of gastric polyps in recent decades, there has not been a significant change in either the key concept of polyp removal or the endoscopic procedure since the first successful treatment of a pedunculated adenomatous polyp with snare polypectomy by Brandt et al. in 1973 [2]. On the other hand, despite the fact that complications associated with endoscopic polypectomy are uncommon in the hands of experienced endoscopists, polypectomy-associated hemorrhage and gastric perforation have been reported $[1,3]$. The decision is especially painful in patients with high risk for complications from endoscopic polypectomy that mandates even more invasive and risky surgical intervention. As a result, some centers proposed biopsy only, rather than excision, even for larger asymptomatic polyps in elderly patients. Indeed, some have even advocated doing nothing for asymptomatic polyps [1]. Although novel endoscopic techniques for polypectomy including the use of hemoclips [4], detachable snares [5], and saline-solution-epinephrine injection plus band ligation [6] have been reported to minimize the risk of bleeding from polypectomy, no alternative low-risk strategy catering for both the diagnosis and treatment of large-sized gastric polyps has been proposed.

We report a high-risk patient with debilitating systemic disease presenting with an obstructive gastric polyp who was successfully treated with detachable snaring without polypectomy.

\section{Case Report}

A 74-year-old woman with senile dementia, end-stage renal disease under regular hemodialysis, congestive heart failure with atrial fibrillation, an ejection fraction of $46 \%$ and a Karnofsky score of 50 presented to our outpatient clinic with complaints of early satiety, intermittent postprandial nausea and vomiting for three months. She denied dysphagia or change in bowel habits. On physical examination, her abdomen was soft with normoactive bowel sounds without tenderness. The liver and spleen were not palpable. Laboratory tests showed a hemoglobin concentration of $11.4 \mathrm{~g} / \mathrm{dl}$ with a mean corpuscular volume of $100.9 \mathrm{fl}$. Serum creatinine concentration was $5.2 \mathrm{mg} / \mathrm{dl}$. With the impression of gastric outlet obstruction or peptic ulcer disease, gastroduodenal endoscopy was arranged after the patient's informed consent. The patient was put in a left decubitus position with a spray of local anesthetics applied over the oropharynx before endoscopy, which revealed a $2.5 \mathrm{~cm}$ pedunculated polyp arising from the posterior wall of the antrum. This polyp was found to be prolapsing into the pylorus of the stomach, causing intermittent gastric outlet obstruction (fig. 1a). After biopsy over the top of the polyp for pathological analysis, the polyp was ligated tightly at the base of the stalk with a detachable snare (Endo-Loop, MAJ-254, Olympus, Tokyo, Japan) (fig. 1b). The whole procedure was performed in an outpatient setting and no complaint of discomfort or complication was noted after the procedure. Pathology later revealed granulation tissue without evidence of malignancy. The symptom of obstruction was relieved one week after snaring. No sign of gastrointestinal hemorrhage including tarry or bloody stool was noted. Endoscopic follow-up three weeks after the procedure revealed a small sessile submucosal elevation with intact mucosa over the previous site of the polyp (fig. 1c). The previous polyp location became inconspicuous with a mild elevation on endoscopic examination six months after the procedure (fig. 1d). The patient was symptom-free on one-year follow-up.

\section{Discussion}

Gastric polyp, which is a female-predominant condition affecting mostly the elderly population, is not uncommon with an incidence of $1-5 \%$ [7]. Although it is mostly asymptomatic and presents as an incidental finding on endoscopic examination, 
associated medical conditions including iron deficiency anemia [8] and acute pancreatitis [9] have been documented. Due to its predominant antral location [7], it has also been reported to cause gastric outlet obstruction $[1,7,8,10-12]$. Although the median size of obstructive polyps is $5 \mathrm{~cm}$, lesions as small as $2 \mathrm{~cm}$ can produce obstructive symptoms [7] such as intermittent dull epigastric pain, bloating, belching, postprandial nausea, and vomiting.

The current standard treatment strategy for gastric polyps causing obstructive symptoms is complete removal either endoscopically or surgically, followed by pathological analysis. Endoscopic resection of pedunculated polyps $1 \mathrm{~cm}$ or greater in diameter is technically complex [5], while surgical excision is not suitable for high-risk patients. Moreover, albeit relatively uncommon, complications from polypectomy including bleeding [1] and gastric perforation [3] have been reported. Indeed, polypectomy-associated hemorrhage has been reported to be as high as $4 \%$ [1]. Our patient was old with impaired performance status, cardiac and renal function. After detailed discussion, her family declined the option of polypectomy.

Our experience suggests that application of a detachable snare for induction of polyp ischemia and necrosis may be an attractive option in selected cases with large-sized polyps and high risk for polypectomy in an outpatient setting under minimal sedation. Adequate tissue from biopsy for pathological analysis is mandatory because it has been reported that the incidence of malignant transformation ranges from $2.1 \%$ in hyperplastic polyps [13] to $40 \%$ in adenomatous polyps [14]. In addition, regular follow-up and endoscopic examination is suggested for patients after the procedure.

In conclusion, we report the first successful experience in the treatment of a high-risk patient with obstructive gastric polyp using a detachable snare without polypectomy. Our results suggest that the procedure may be a feasible option for patients unsuitable for endoscopic or surgical excision of benign gastric polyps.

\section{Disclosure Statement}

The authors have no conflicts of interest to declare. 


\begin{tabular}{|c|c|c|c|}
\hline $\begin{array}{r}\text { Case Reports in } \\
\text { Gastroenterology }\end{array}$ & $\begin{array}{l}\text { Case Rep Gastroenterol 2011;5:267-271 } \\
\text { DOI: } 10.1159 / 000328443\end{array}$ & $\begin{array}{l}\text { Published online: } \\
\text { May 3, } 2011\end{array}$ & $\begin{array}{l}\text { @ } 2011 \text { S. Karger AG, Basel } \\
\text { ISSN } 1662-0631 \\
\text { www.karger.com/crg }\end{array}$ \\
\hline
\end{tabular}

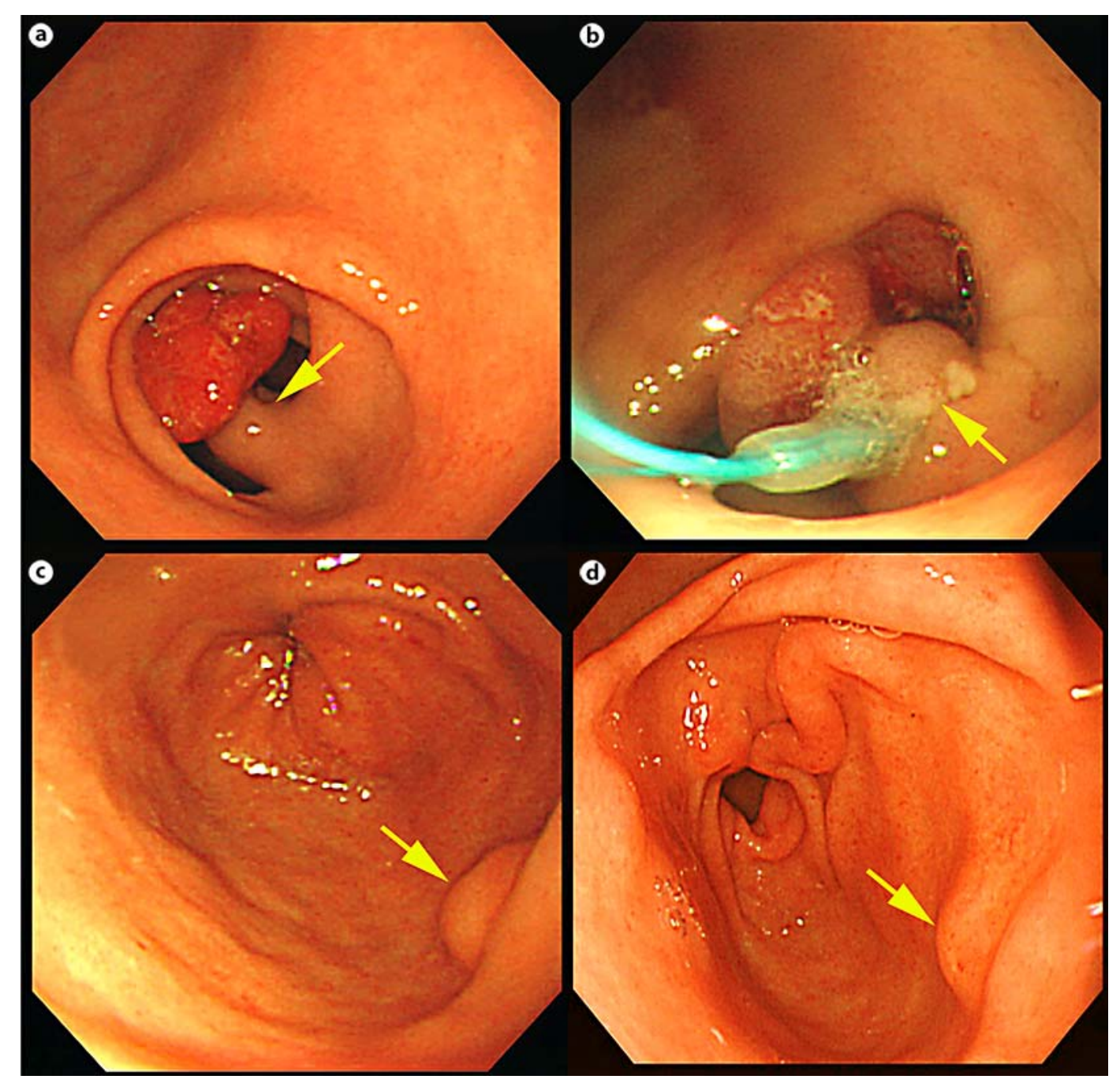

Fig. 1. a Endoscopic picture demonstrating a pedunculated polyp over the gastric antrum near the pyloric ring with an easily identifiable stalk (arrow). b Application of a detachable snare over the base of the stalk (arrow). Note the ischemic change of the polyp. c Endoscopic follow-up three weeks after the procedure showing a small sessile submucosal elevation with intact mucosa over the previous site of snaring (arrow). d Inconspicuous elevation over the previous polyp location on endoscopic examination six months after the procedure (arrow).

\section{References}

1 Freeman HJ: Endoscopic excision of a prolapsing malignant polyp which caused intermittent gastric outlet obstruction. World J Gastroenterol 2005;11:5245-5247.

2 Brandt L, Frankel A, Waye JD: Endoscopic nonoperative gastric polypectomy. Am J Dig Dis 1973;18: 1087-1090.

3 Katsinelos P, Beltsis A, Paroutoglou G, Galanis I, Tsolkas P, Mimidis K, Pilpilidis I, Baltagiannis S, Kamberis E, Papaziogas B: Endoclipping for gastric perforation after endoscopic polypectomy: an alternative treatment to avoid surgery. Surg Laparosc Endosc Percutan Tech 2004;14:279-281.

4 Sobrino-Faya M, Martinez S, Gomez Balado M, Lorenzo A, Iglesias-Garcia J, Iglesias-Canle J, Dominquez Munoz JE: Clips for the prevention and treatment of postpolypectomy bleeding (hemoclips in polypectomy). Rev Esp Enferm Dig 2002;94:457-462. 
5 Akahoshi K, Kojima H, Fujimaru T, Kondo A, Kubo S, Furuno T, Nakanishi K, Harada N, Nawata H: Grasping forceps assisted endoscopic resection of large pedunculated GI polypoid lesions. Gastrointest Endosc 1999;50:95-98.

6 Akahoshi K, Yoshinaga S, Fujimaru T, Kondoh A, Higuchi N, Furuno T, Oya M: Endoscopic resection with hypertonic saline-solution-epinephrine injection plus band ligation for large pedunculated or semipedunculated gastric polyp. Gastrointest Endosc 2006;63:312-316.

7 Parikh M, Kelley B, Rendon G, Abraham B: Intermittent gastric outlet obstruction caused by a prolapsing antral gastric polyp. World J Gastrointest Oncol 2010;2:242-246.

8 Alper M, Akcan Y, Belenli O: Large pedunculated antral hyperplastic gastric polyp traversed the bulbus causing outlet obstruction and iron deficiency anemia: endoscopic removal. World J Gastroenterol 2003;9:633-634.

9 de la Cruz RA, Albillos JC, Oliver JM, Dhimes P, Hernandez T, Trapero MA: Prolapsed hyperplastic gastric polyp causing pancreatitis: case report. Abdom Imaging 2001;26:584-586.

10 Chen HW, Lu CH, Shun CT, Lin MT, Tsang YM: Gastric outlet obstruction due to giant hyperplastic gastric polyps. J Formos Med Assoc 2005;104:852-855.

11 Gencosmanoglu R, Sen-Oran E, Kurtkaya-Yapicier O, Tozun N: Antral hyperplastic polyp causing intermittent gastric outlet obstruction: case report. BMC Gastroenterol 2003;3:16.

12 Abou-Assi SG, Mihas AA, Joseph RM, Subramony C: Endoscopic hemoclip application for the treatment of a large gastric polyp causing intermittent outlet obstruction. Gastrointest Endosc 2003;57:433-435.

13 Daibo M, Itabashi M, Hirota T: Malignant transformation of gastric hyperplastic polyps. Am J Gastroenterol 1987;82:1016-1025.

14 Orlowska J, Jarosz D, Pachlewski J, Butruk E: Malignant transformation of benign epithelial gastric polyps. Am J Gastroenterol 1995;90:2152-2159. 